\title{
Comparative study between Sustained Low Efficiency Hemodialysis and Online Hemodiafiltration in Critically Ill patients with Acute Kidney Injury
}

Mostafa Abdel Fattah El-Ballat ${ }^{1}$, Mohamed Saeed El-Shorbagy ${ }^{2}$,

Mohamed Ahmed El-Sayed ${ }^{1}$, and Abdel Aziz Refaat Abdel Aziz ${ }^{2}$ *

Department of ${ }^{1}$ Internal Medicine and ${ }^{2}$ Clinical Pathology, Faculty of Medicine,

Al-Azhar University, Cairo, Egypt

*Corresponding author: Abdel Aziz Refaat Abdel Aziz, Mobile: $( \pm 20) 01116686028$, E-Mail: abdelaziz.refaat@gmail.com

\begin{abstract}
Background: acute kidney injury (AKI) has arisen as a global public health problem and associated with high morbidity and mortality where the AKI mortality is more than $50 \%$. It is a serious complication frequently occurred in ICU In hospitalized patients, $15 \%$ of them developed AKI and around 40\% of AKI patients were referred to ICU.

Objective: The aim of this study was to compare between effect of Sustained Low Efficiency Hemodialysis and Online Hemodiafiltration in Critically Ill patients with Acute Kidney Injury.

Patients and Methods: This prospective study included a total of forty (age and sex matched) patients with Acute Kidney Injury (AKI) who were critically ill, attending at Nephrology Unit, Bab El-Shaareya, Al-Azhar University Hospitals. The patients were divided into 2 groups; Group (A): 20 patients on Sustained Low Efficiency Hemodialysis (SLED) and Group (B): 20 patients on Online Hemodiafiltration (OLHDF)

Results: there was no significant difference between the two groups as regard Intradialytic hypotension ( 2 patients $(10 \%)$ in group 1 and 5 patients in group $2(25 \%)$ p-value $=0.2)$. There was no significant difference between the two groups as regard weaning from ventilator (4 patients (40\%) in group 1 and 3 patients in group 2 (42.8\%) p-value $=0.5$ ).

Conclusion: Online haemodiafiltration (OL-HDF) showed to be better than IHD-LI in many aspects but there was no statistically significant difference in mortality, allowing us to recommend as first choice OL-HDF of treatment proposed for critically ill patients with acute kidney injury.
\end{abstract}

Keywords: Sustained Low Efficiency Hemodialysis, Online Hemodiafiltration, Acute Kidney Injury.

\section{INTRODUCTION}

Acute kidney injury is a common occurrence in critically ill patients, with incidence rates of occurrence varying from 5 to $60 \%$ and a trend towards higher rates (30 to $60 \%$ ) when using the risk, injury, failure, loss of kidney function, end stage renal failure (Risk, Injury, Failure, Loss of kidney function, RIFLE) or Acute Kidney Injury (AKI) Network (AKIN) classification ${ }^{(\mathbf{1})}$.

Acute kidney injury is an independent risk factor for increased morbidity and mortality ${ }^{(2)}$. The term 'acute kidney injury' (AKI) is currently recognized as the preferred nomenclature for the complex clinical syndrome formerly known as acute renal failure (ARF). This transition in terminology also serves to emphasize that the spectrum of disease is much broader than the subset of patients who experience renal failure requiring dialysis treatment (3).

AKI occurs in a variety of settings, and has clinical manifestations ranging from a minimal elevation in serum creatinine levels to anuric renal failure. In fact, AKI exists along a continuum of disease: the acute decline in kidney function is often secondary to an injury that causes functional or structural changes in the kidneys. As the severity of the underlying renal injury increases, the risk of unfavorable outcome rises ${ }^{(4)}$.
Renal replacement therapy (RRT) is necessary in about $6 \%$ of critically ill patients, according to a large multinational, multicenter survey, and it is provided as supportive treatment to AKI patients, preventing additional disorders (hypervolemia, metabolic acidosis, progressive uremia, and hyperkalemia) ${ }^{(5)}$.

There is a long debate about the time to start, and the ideal treatment for RRT in critically ill patients with sepsis, considering that the majority have multiorgan dysfunction and hemodynamic instability (6).

Controversies begin since the time of treatment's onset, dose prescription, mode and mechanism for solute's remotion? (convection, diffusion, adsorption, or mixed), and about convection therapies there are discussion regarding the replacement volume, although some studies recommend larger volumes of replacement as beneficial, these results are not conclusive in other studies ${ }^{(7)}$.

Online hemodiafiltration (OL-HDF) is a mixed technique that combines a standard haemodialysis diffusive transport with a significant amount of convective transport, thus provides a greater clearance of medium and large molecular-size, which are difficult to remove by diffusion alone ${ }^{(1)}$. 
This technique requires a biocompatible high flux and permeability membranes, as well as precise machines with ultrafiltration control and ultrapure dialysate fluid for replacement. There is a high economic impact in OL - HDF implementation, so it is necessary to know the real benefits for applying ${ }^{\left({ }^{8}\right)}$.

This dialysis technique has been used in renal chronic patients in whom large and medium-size molecules removal ameliorates chronic complications in hemodialysis patients and decrease mortality ${ }^{(9)}$.

Currently by the convective properties, entrapment and elimination of proinflammatory molecules has begun to be used in patients with AKI (10).

In Egypt Continuous Renal Replacement Therapy (CRRT) is not widely available, so that patients are treated with SLED, IHD-LI or IHD-HI or intermittent OL-HDF and there are no comparative studies about benefits between the procedures. (Write the reference of this paragraph) So, this study is developed in order to consolidate and choose the best procedure adapted to developing countries.

The aim of this study was to compare between effect of Sustained Low Efficiency Hemodialysis and Online Hemodiafiltration in Critically Ill patients with Acute Kidney Injury.

\section{PATIENTS AND METHODS}

This prospective study included a total of forty (age and sex matched) patients with Acute Kidney Injury (AKI) who were critically ill, attending at • Nephrology Unit, Bab El-Shaareya, Al-Azhar University Hospitals.

Approval of the Al-Azhar University ethical committee and a written informed consent from all the subjects were obtained.

The 40 patients were divided into 2 groups; Group (A): 20 patients on Sustained Low Efficiency Hemodialysis (SLED) and Group (B): 20 patients on Online Hemodiafiltration (OLHDF)

\section{Inclusion criteria:}

1. Patients aging 18 years or more.

2. All patients presenting with a critical illness who develop acute kidney injury either at presentation or after admission.

3. AKI as defined according to the AKIN criteria (AKINIII).

\section{Exclusion criteria:}

1. Age $<16$ years,

2. Patients with chronic kidney disease including ESRD who are on Renal Replacement Therapy (RRT).

3. Patients who have malignant diseases.

4. Patients with hepatic impairment.
All patients have been subjected to the following:

1- Full history taking from patients if possible or from relatives.

2- Complete clinical examination.

3- Basic laboratory work-up: (serum creatinine, urea, urea reduction ratio (URR), $\mathrm{Na}^{+}, \mathrm{K}^{+}$, Albumin, and $\mathrm{CBC}$ ).

4- Dialysis related clinical complications especially: Intradialytic Hypotension and arrhythmias

5- Mortality rate recording.

Patients were assigned on two groups according the treatment regimen available in different institutions:

Group A: (20 patients) who received IHD-LI, the first three sessions were daily with an increasing time of 30 minutes from 150 minutes until 210 minutes, with an increasing blood flow pump (QB) of $50 \mathrm{ml} / \mathrm{min}$ from 250 to $400 \mathrm{ml} / \mathrm{min}$ and dialysate flow (QD) of $500 \mathrm{ml} / \mathrm{min}$. Since the fourth treatment session patients received standard therapy of 210 minutes with QB $400 \mathrm{ml} / \mathrm{min}$, and QD $500 \mathrm{ml} / \mathrm{min}$ every 48 hours.

Group B: (20 patients) who received OL-HDF, the first three sessions were daily with mixed replacement (pre and post dilutional) therapy according the following scheme:

- First session: 180 minutes QB $350 \mathrm{ml} / \mathrm{min}$ QD 800 $\mathrm{ml} / \mathrm{min}$, volume replacement $84 \mathrm{ml} / \mathrm{min}$.

Second session: 210 minutes QB $400 \mathrm{ml} / \mathrm{min}$ QD 800 $\mathrm{ml} / \mathrm{min}$, volume replacement $100 \mathrm{ml} / \mathrm{min}$.

Third session: 240 minutes QB $400 \mathrm{ml} / \mathrm{min}$ QD 800 $\mathrm{ml} / \mathrm{min}$, volume replacement $120 \mathrm{ml} / \mathrm{min}$.

- Since the fourth session the patients received the same RRT method that consisting on IHD-LI in sessions of 240 minutes, QB $400 \mathrm{ml} / \mathrm{min}$, QD 500 $\mathrm{ml} / \mathrm{min}$. Treatments were developed with Fresenius 4008S machine with on line hemodiafiltration module, polysulfone filters high flux were used in IHD-LI and high flux cartridge in OL-HDF.

\section{Statistical analysis}

Recorded data were 3415 nalysed using the statistical package for social sciences, version 20.0 (SPSS Inc., Chicago, Illinois, USA). Quantitative data were expressed as mean \pm standard deviation (SD). Qualitative data were expressed as frequency and percentage.

\section{The following tests were done:}

- Independent-samples t-test of significance was used when comparing between two means.

- Chi-square $\left(\mathrm{x}^{2}\right)$ test of significance was used in order to compare proportions between two qualitative parameters.

- The confidence interval was set to $95 \%$ and the margin of error accepted was set to $5 \%$. The pvalue was considered significant as the following: 
- Probability (P-value)

- P-value $<0.05$ was considered significant.

$\mathrm{P}$-value $<0.001$ was considered as highly significant.

$\mathrm{P}$-value $>0.05$ was considered insignificant.
Table (1): Shows comparison between the two groups as regard socio-demographic including sex, diabetes mellitus (DM), hypertension (HTN) and Mechanical ventilation. There was no significant difference between the two groups.

\section{RESULTS}

Table (1): Socio-demographic data of the studied groups.

\begin{tabular}{|c|c|c|c|c|c|}
\hline $\begin{array}{c}\text { Socio-demographic } \\
\text { data }\end{array}$ & Group 1 & Group 2 & Test & P value & Significance \\
\hline $\begin{array}{l}\text { Age (years) } \\
\text { Mean } \pm \text { SD } \\
\text { Range }\end{array}$ & $\begin{array}{c}57.9 \pm 15.54 \\
18-80\end{array}$ & $\begin{array}{c}50.2 \pm 13.48 \\
19-72\end{array}$ & $* * *$ & 0.076 & NS \\
\hline $\begin{array}{l}\text { Sex } \\
\text { Male } \\
\text { Female }\end{array}$ & $\begin{array}{ll}\text { No } & \% \\
17 & 85 \\
3 & 15\end{array}$ & $\begin{array}{ll}\text { No } & \% \\
13 & 65 \\
7 & 35\end{array}$ & * & 0.13 & NS \\
\hline DM & $\begin{array}{ll}\text { No } & \% \\
10 & 50\end{array}$ & $\begin{array}{cc}\text { No } & \% \\
11 & 55\end{array}$ & * & 0.36 (NS) & NS \\
\hline HTN & $\begin{array}{cc}\text { No } & \% \\
13 & 65\end{array}$ & $\begin{array}{cc}\text { No } & \% \\
11 & 55\end{array}$ & $*$ & 0.37 (NS) & NS \\
\hline MV & $\begin{array}{cc}\text { No } & \% \\
10 & 50\end{array}$ & $\begin{array}{cc}\text { No } & \% \\
7 & 35\end{array}$ & $*$ & $0.26(\mathrm{NS})$ & NS \\
\hline
\end{tabular}

*Chi-square test $\quad * *$ Mann-Whitney U NS (non- significant) S (significant)

HS ( highly significant)

Table (2): Shows comparison between the two groups as regard laboratory data including serum creatinine, albumin, $\mathrm{Na}^{+}, \mathrm{K}^{+}$and $\mathrm{Hb}$ concentration and Total WBCs count $\left(\times 10^{9} / 1\right)$. There were no significant differences between the two groups as regard all of laboratory parameters.

Table (2): Comparison between the two groups as regard laboratory data.

\begin{tabular}{|c|c|c|c|c|}
\hline Laboratory data & Group 1 & Group 2 & P value & Significance \\
\hline $\begin{array}{l}\text { Serum creatinine }(\mathrm{mg} / \mathrm{dl}) \\
\text { Mean } \pm \text { SD } \\
\text { Range }\end{array}$ & $\begin{array}{c}4.9 \pm 0.85 \\
3.5-6.5\end{array}$ & $\begin{array}{c}4.57 \pm 1.09 \\
3.2-6.7\end{array}$ & 0.2 & NS \\
\hline $\begin{array}{l}\text { Serum albumin }(\mathrm{g} / \mathrm{dl}) \\
\text { Mean } \pm \text { SD } \\
\text { Range }\end{array}$ & $\begin{array}{c}3.6 \pm 0.42 \\
3-4.6\end{array}$ & $\begin{array}{c}3.3 \pm 0.65 \\
24.5-\end{array}$ & 0.06 & NS \\
\hline $\begin{array}{l}\text { Hb }(g / d l) \\
\text { Mean } \pm \text { SD } \\
\text { Range }\end{array}$ & $\begin{array}{c}9.6 \pm 1.71 \\
6.3-12.2\end{array}$ & $\begin{array}{l}9.5 \pm 1.37 \\
6.9-11.9\end{array}$ & 0.74 & NS \\
\hline $\begin{array}{l}\text { Serum Na } \mathrm{Na}^{+}(\mathrm{mmol} / \mathrm{l}) \\
\text { Mean } \pm \mathrm{SD} \\
\text { Range }\end{array}$ & $\begin{array}{c}135.6 \pm 5.04 \\
122-144\end{array}$ & $\begin{array}{c}135.7 \pm 4.41 \\
128-143\end{array}$ & 0.86 & NS \\
\hline $\begin{array}{l}\text { Serum } \mathrm{K}^{+}(\mathrm{mmol} / \mathrm{l}) \\
\text { Mean } \pm \text { SD } \\
\text { Range }\end{array}$ & $\begin{array}{l}5.2 \pm 0.77 \\
4.2-7.2\end{array}$ & $\begin{array}{l}5.6 \pm 0.91 \\
4.1-7.5\end{array}$ & 0.2 & NS \\
\hline $\begin{array}{l}\text { Total WBCs count }\left(\times 10^{9} / 1\right) \\
\text { Mean } \pm \text { SD } \\
\text { Range }\end{array}$ & $\begin{array}{c}16.3 \pm 3.41 \\
12-25\end{array}$ & $\begin{array}{c}14 \pm 1.31 \\
12-16\end{array}$ & 0.26 & NS \\
\hline
\end{tabular}

*Chi-square test $\quad * *$ Mann-Whitney U NS (non- significant) S (significant) HS ( highly significant) 
Table (3): Shows comparison between the two groups as regard most important intradialytic complications (intradialytic hypotension and arrhythmia). There was no significant difference between the two groups.

Table (3): Comparison between the two groups as regard intradialytic complications.

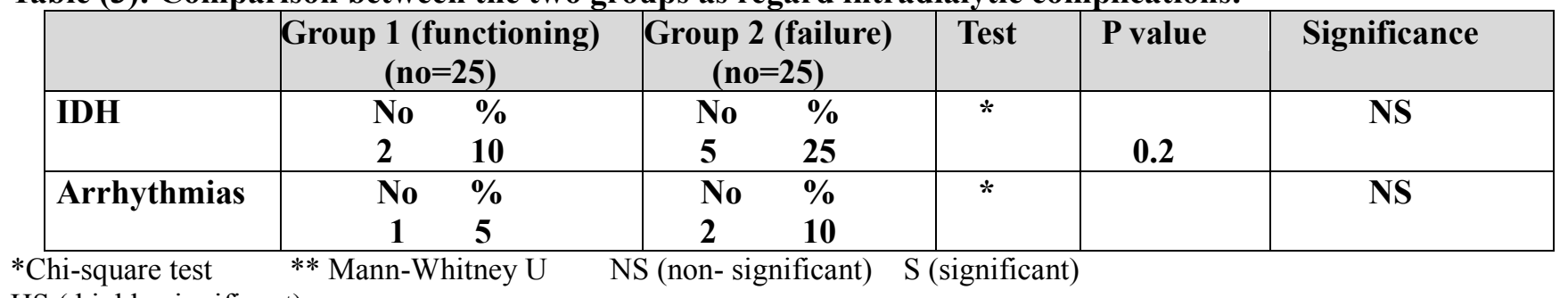

HS ( highly significant)

Table (4): Shows comparison between the two groups as regard indicators of clinical outcomes ( 2 weeks all mortality, Weaning from ventilator, ICU stay and Hospital stay ). There was no significant difference between the two groups as regard 2 weeks all -mortality and weaning from ventilator ,however there was a significant difference between the two groups as regard ICU stay and a highly significant difference between the two groups as regard Hospital stay.

Table (4): Comparison between the two groups as regard clinical outcome.

\begin{tabular}{|c|c|c|c|c|c|}
\hline Clinical data & $\begin{array}{c}\text { Group 1 } \\
\text { (functioning) } \\
(\text { no= }=25)\end{array}$ & $\begin{array}{c}\text { roup } 2 \text { (failure) } \\
(\mathrm{no}=25)\end{array}$ & Test & P value & Significance \\
\hline 2 weeks all -mortality & $\begin{array}{ll}\text { No } & \% \\
8 & \mathbf{4 0} \\
\end{array}$ & $\begin{array}{ll}\text { No } & \% \\
11 & 55 \\
\end{array}$ & * & 0.26 & NS \\
\hline $\begin{array}{l}\text { Weaning from } \\
\text { ventilator }\end{array}$ & $\begin{array}{cc}\text { No } & \% \\
4 & 40 \\
\end{array}$ & $\begin{array}{lr}\text { No } & \% \\
3 & 42.8 \\
\end{array}$ & $*$ & 0.34 & NS \\
\hline $\begin{array}{l}\text { ICU stay } \\
\text { (in servivors and } \\
\text { weaned cases from } \\
\text { vent.) }\end{array}$ & $\begin{array}{c}14.4 \pm 3.34 \\
10-22\end{array}$ & $\begin{array}{c}17.4 \pm 3.35 \\
13-23\end{array}$ & $* *$ & 0.04 & $\mathbf{S}$ \\
\hline $\begin{array}{l}\text { Hospital stay } \\
\text { (in servivors and } \\
\text { weaned cases from } \\
\text { vent.) }\end{array}$ & $\begin{array}{c}18.8 \pm 2.26 \\
14-22\end{array}$ & $\begin{array}{c}25.8 \pm 6.01 \\
19-39\end{array}$ & $* *$ & $<0.01$ & HS \\
\hline
\end{tabular}

*CHI-SQUARE TEST $\quad * * \quad$ Mann-Whitney U NS (non- significant) $\quad$ S(significant) HS( highly significant)

\section{DISCUSSION}

The aim of the current study was to demonstrate advantages of treatment with online hemodiafiltration (own scheme) versus intermittent hemodialysis high flux low intensity in patients with sepsis and acute kidney injury. Primary outcomes evaluated were mortality, mechanical ventilation dependence and permanence at intensive care unit. Two groups undergoing treatment for intermittent SLED (Group A: n 20) vs. online hemodiafiltration (Group B: $\mathrm{n} 20$ ).

As regard age, years (mean \pm S.D.) was $54 \pm 14.88$ (57.9 \pm 15.54 in group A and $50.2 \pm 13.48$ in group B). These results are near to results in a similar study by (Azkarate et al. ${ }^{(5)}$. There was no significant difference between the two groups.

As regard sex there were 30 males and 10 females (17 males versus 3 females in group A while in group B, 13 males versus 7 females), there was no significant difference between the two groups.
Serum creatinine, $\mathrm{mg} / \mathrm{dl}$ (mean \pm S.D.) was 4.7515 $\pm 0.98782(4.9 \pm 0.85$ in group $A$ and $4.57 \pm 1.09$ in group B. There was no significant difference between the two groups as regard serum creatinine.

As regard prevalence of DM, 10 was diabetic $(50 \%)$ in group A and 11 in group B (55\%).There was no significant difference between the two groups.

As regard prevalence of HTN, 13 was hypertensive (65\%) in group 1 and 11 in group $2(55 \%)$. There was no significant difference between the two groups.

As regard mechanical ventilation, 10 was on mechanical ventilation (50\%) in group 1 and 7in group $2(35 \%)$ there was no significant difference between the two groups.

The reported mortality rate associated with AKI is 20-90\%, which has not changed significantly over the last 15 years. Mortality rate depends on the patient's general condition, age, and the severity of illness. Among patients who are admitted to the ICU because of AKI, older patients experience higher rates of AKI. 
There used to be no uniform definition of AKI in the literature until the Acute Kidney Injury Network (AKIN) developed a new definition based on scientific investigation. As minor increases in serum creatinine $(\geq 0.3 \mathrm{mg} / \mathrm{dl})$ are associated with increased mortality, AKIN chose changes in serum creatinine as the basis of their definition of AKI. Besides mortality, AKI increases other morbidities, which are associated with increased costs, increased length of hospital stays, and increased risk of developing chronic kidney disease (CKD), including end-stage kidney disease ${ }^{(\mathbf{1 0})}$.

In this study patients with RRT showed high mortality (47.5\%), near to the result reported by Schrier et al. ${ }^{(11)}$. However, As regard 2 weeks all-mortality, there was no significant difference between the two groups.

In our study serum sodium, mmol/L (mean \pm S.D.) was $135.6450 \pm 4.67804(135.6 \pm 5.04)$ in group $\mathrm{A}$ and $135.7 \pm 4.41$ in group B). As regard serum sodium, there was no significant difference between the two groups.

There was no significant difference between the two groups regarding serum potassium, $\mathrm{mmol} / \mathrm{L}$ (mean \pm S.D.) was $5.4067 \pm .85487(5.2 \pm 0.77)$ in group A and $5.6 \pm 0.91$ in group B).

As regard serum albumin, $g / d$ l (mean \pm S.D.) was $3.4325 \pm .56085(3.6 \pm 0.42$ in group $A$ and $3.3 \pm 0.65$ in group $\mathrm{B}$ ), there was no significant difference between the two groups .

As regard $\mathrm{Hb}$ concentration, g/dl (mean \pm S.D.) was $9.5275 \pm 1.52954(9.6 \pm 1.71$ in group $\mathrm{A}$ and $9.5 \pm 1.37$ in group $B$ ) there was no significant difference between the two groups.

Intradialytic hypotension (IDH), a common complication of ultrafiltration during hemodialysis therapy, is associated with high mortality and morbidity. IDH, defined as a nadir systolic blood pressure of less than $90 \mathrm{mmHg}$ on more than $30 \%$ of treatments, is a relevant definition and is correlated with mortality. Risk factors for IDH include patient demographics, antihypertensive medication use, larger interdialytic weight gain, and dialysis prescription features as dialysate sodium, high ultrafiltration rate, and dialysate temperature. A high frequency of IDH events carries a substantial death risk ${ }^{(\mathbf{1 2})}$.

In our study there was no significant difference between the two groups as regard Intradialytic hypotension (2 patients $(10 \%)$ in group $\mathrm{A}$ and 5 patients in group B $(25 \%)$ p-value $=0.2)$.

Sudden death in patients on hemodialysis is believed to be due to arrhythmia. Arrhythmia is common during hemodialysis and is triggered by hemodynamic and electrolyte imbalance ${ }^{(\mathbf{1 2})}$.

We found that there was no significant difference between the two groups as regard arrhythmia ( 1 patients $(5 \%)$ in group 1 and 2 patients in group $2(10 \%) \mathrm{p}$-value $=0.5$ ).
As regard Weaning from ventilator, there was no significant difference between the two groups ( 4 patients $(40 \%)$ in group 1 and 3 patients in group 2 $(142.8 \%)$ p-value $=0.5)$.

As regard ICU stay, there was no significant difference between the two groups, also no significant difference between the two groups Hospital stay these results are in agreement with Daríoe et al. ${ }^{(1)}$ who found a beneficial effect of online HDF on ICU and hospital stay.

\section{CONCLUSION}

It could be concluded that OL-HDF showed to be better than IHD-LI in many aspects but there was no statistically significant difference in mortality, allowing us to recommend as first choice OL-HDF of treatment proposed for critically ill patients with acute kidney injury.

\section{REFERENCES}

1. Daríoe J, Manuel G, Ana A et al. (2017): Intermittent hemodialysis low intensity vs. on line hemodiafiltration in critically ill patients with sepsis and acute kidney injury. Choosing the best treatment in a developing country. Journal of Nephrology and Therapeutics, 7:299-303.

2. Maduell F, Rodríguez N, Sahdalá L et al. (2014): Impact of the 5008 monitor software update on total convective volume. Nefrologia, 34:599-604.

3. Lombardi R, Rosa-Diez G, Ferreiro A et al. (2014): Acute Kidney Injury in Latin America: A view on renal replacement therapy resources. Nephrol Dial Transplant, 29:1369-1376.

4. Zhang $\mathbf{Z}$ (2015) Biomarkers, diagnosis and management of sepsis-induced acute kidney injury: a narrative review. Heart Lung Vessel., 7:64-73.

5. AzkarateI, Choperena G, Salas E et al. (2015): Epidemiology and prognostic factors of severe sepsis / septic shock. Six years of evolution. Medicina Intensiva, 40: 18-25.

6. Farrington K, Davenport A (2013) HeESHOL study: Hemodiafiltration improves survival-but how? Kidney Int., 83: 979-981.

7. Rama I, Llaudó I, Fontova P et al. (2016): Online hemodiafiltration improves inflammatory state in dialysis patients: A longitudinal study. PLOS ONE, 11: e0164969.

8. Nubé MJ (2016): Hemodiafiltration: Theory, Technology and Clinical Practice, (๑) Springer International Publishing Switzerland. DOI 10.1007/978-3-319-23332-1_11.

9. National Kidney Foundation (2015): KDOQI clinical practice guideline for hemodialysis adequacy: 2015 update. Am J Kidney Dis., 66: 884-930.

10. Marcelli D, Scholz C, Ponce P et al. (2015): High-volume postdilution hemodiafi ltration is a feasible option in routine clinical practice. Artif Organs, 39:142-9.

11.Schrier RW, Wang W, Poole B et al. (2004): Acute renal failure: Definitions, diagnosis, pathogenesis, and therapy. J Clin Invest., 114: 5-14.

12.Zhang L, Yang J, Eastwood GM et al. (2015): Extended daily dialysis versus continuous renal replacement therapy for acute kidney Injury. Am J Kidney Dis., 66(2):322-30. 